\title{
Apolipoprotein E polymorphism is associated with susceptibility to schizophrenia among Saudis
}

\author{
Saeed Mohammad Al-Asmary ${ }^{1}$, Saeed Kadasah², Misbahul Arfin ${ }^{3}$, Mohammad Tariq $^{3}$, \\ Abdulrahman Al-Asmari ${ }^{3}$
}

\begin{abstract}
${ }^{1}$ Department of Neuropsychiatry, Riyadh Military Hospital, Riyadh, Saudi Arabia ${ }^{2}$ Department of Psychiatry, Riyadh Military Hospital, Riyadh, Saudi Arabia ${ }^{3}$ Research Center, Riyadh Military Hospital, Riyadh, Saudi Arabia
\end{abstract}

Submitted: 1 May 2013

Accepted: 10 September 2013

Arch Med Sci 2015; 11, 4: 869-876

DOI: 10.5114/aoms.2015.53308

Copyright @ 2015 Termedia \& Banach

\section{Abstract}

Introduction: Apolipoprotein E (APOE) genotypes influence the phenotype of several neurodegenerative disorders including Alzheimer's and Parkinson disease and may affect schizophrenia pathogenesis. This study was undertaken to determine the association between APOE gene polymorphisms and schizophrenia in the Saudi population.

Material and methods: APOE allele and genotype frequencies were studied in 380 Saudi subjects including schizophrenia patients and matched controls using polymerase chain reaction (PCR) and reverse-hybridization techniques.

Results: The frequencies of the APOE allele $\varepsilon 2$ and genotypes $\varepsilon 2 / \varepsilon 3$ and $\varepsilon 2 / \varepsilon 4$ were significantly higher in the schizophrenia patients as compared to controls, suggesting that the $\varepsilon 2$ allele and its heterozygous genotypes may increase the susceptibility to schizophrenia. In contrast, the frequencies of the $\varepsilon 3$ allele and $\varepsilon 3 / \varepsilon 3$ genotype were lower in patients as compared to controls, suggesting a protective effect of APOE $\varepsilon 3$ for schizophrenia. This study indicated that APOE $\varepsilon 4$ was differentially associated with schizophrenia depending on the symptoms as the frequency of the $\varepsilon 4$ allele was significantly higher in schizophrenia patients with positive symptoms. By contrast, no significant association between APOE $\varepsilon 4$ and schizophrenia patients with negative symptoms was observed. Genotypes $\varepsilon 2 / \varepsilon 2$ and $\varepsilon 4 / \varepsilon 4$ were absent in patients and controls. Moreover, the age of onset was significantly lower in patients with the APOE $\varepsilon 2 / \varepsilon 3$ genotype. There was no significant difference in the frequencies of APOE alleles and genotypes between male and female schizophrenia patients.

Conclusions: The results of this study clearly show that APOE alleles and genotypes are associated with risk of developing schizophrenia and early age of onset in Saudis.

Key words: schizophrenia, apolipoprotein E (APOE), polymorphism, Saudis.

\section{Introduction}

Schizophrenia is a clinical syndrome of severe mental illness characterized by a breakdown of thought processes, hallucinations, delusions and functional deterioration. According to the World Health Organization estimate, schizophrenia affects around 24 million people worldwide, with a prevalence ranging from $0.7 \%$ to $1.1 \%$ and with a lifetime morbidity risk of $0.5-2.7 \%[1,2]$. Due to its early age of onset and the lifelong disabili-

\author{
Corresponding author: \\ Abudlrahman Al-Asmari \\ Research Center \\ Riyadh Military Hospital \\ P.O. Box 7897 \\ Riyadh 11159, Saudi Arabia \\ Phone: 96614777714 \\ ext. 25100 \\ Fax: 96614777714 \\ ext. 23066 \\ E-mail: abdulrahman. \\ alasmari@gmail.com
}


ty, which invariably brings emotional and financial devastation to its victims and their families, schizophrenia is considered one of the most catastrophic mental illnesses [3, 4]. In spite of extensive studies, schizophrenia still remains a diagnosis of exclusion, since none of its clinical features are pathognomonic, and, by and large, biochemical imaging, physiologic and psychological tests lack the sensitivity and specificity required for a firm diagnosis [5]. The causes and pathogenesis of schizophrenia remain vexingly obscure. Recent studies clearly suggest that schizophrenia is a multifactorial disease involving several genes with each susceptibility gene having only a modest individual effect [6]. A combination of complex genetic and environmental processes that may cause the disease have been proposed [7]. Genetic studies have implicated several susceptibility loci, but the clinical impact of these loci in the pathogenesis of schizophrenia is yet to be established.

There is ample evidence to suggest that cognitive dysfunction in schizophrenia is closely associated with alterations in synapses, dendritic spines and myelin [8-10]. Lipoprotein cholesterol being an indispensable component of synapses and myelin, its availability in oligodendrocytes is a rate-limiting factor in maturation and repair of neurons $[11,12]$. Apolipoprotein E (APOE), being closely associated with uptake and distribution of cholesterol in the brain and other parts of body, is an excellent candidate for a pathologic role in cardiovascular and neurological disorders including schizophrenia $[13,14]$. Apolipoprotein E synthesized in astrocytes and oligodendrocytes plays a critical role in growth development and repair of neurons $[15,16]$. Significantly altered APOE levels in brains of people with schizophrenia have been reported [17-19].

Apolipoprotein E, a 34-kDa glycosylated protein, is composed of 299 amino acids encoded by a four exon polymorphic gene on chromosome 19q13.2. The gene encoding APOE has three polymorphic variants in humans designated as $\varepsilon 2, \varepsilon 3$ and $\varepsilon 4$. These variants differ from one another by the presence of either a $\mathrm{C}$ or a $\mathrm{T}$ nucleotide at codons 112 and 158. These three alleles encode different APOE isoforms which vary significantly in structure and function including receptor binding capacity and lipid metabolism [20]. As each individual human being carries two allelic copies in a gene, six possible genotypes $(\varepsilon 2 / \varepsilon 2, \varepsilon 3 / \varepsilon 3$, $\varepsilon 2 / \varepsilon 3, \varepsilon 3 / \varepsilon 4, \varepsilon 2 / \varepsilon 4$, and $\varepsilon 4 / \varepsilon 4$ ) are formed by different combinations of these three alleles [21, 22]. The frequency of these genotypes differs significantly among different ethnic groups; however, APOE $\varepsilon 3 / \varepsilon 3$ is the most predominant genotype and $\varepsilon 3$ the most common allele in the majority of the population [23-25].
Evidence suggests that the APOE genotype may influence the phenotype of several neuropsychiatric illnesses $[26,27]$. The association between APOE genotype and schizophrenia was first reported by Harrington et al. in 1995 [28]. However, subsequent studies on APOE genotype distribution in schizophrenia have produced conflicting findings [29-38].

The prevalence of psychiatric disorder is quite high in the Kingdom of Saudi Arabia (KSA) and other Arab countries [39]. The Saudi population, being a closed and isolated society with a high rate of consanguinity (inbreeding), may represent a valuable resource for studying genetic etiology of schizophrenia as compared to other heterogeneous populations. In this study we examined the APOE allele/genotype frequencies in Saudi schizophrenic patients.

\section{Material and methods}

\section{Subjects}

A total of 380 subjects including 180 schizophrenia patients visiting a psychiatric clinic and 200 age- and sex-matched healthy controls visiting a community health clinic of Prince Sultan Military Medical City, Riyadh were recruited to this study. All the subjects were biologically unrelated Saudis. The diagnosis of schizophrenia was based on the criteria mentioned in the American Psychiatric Association Diagnostic and Statistical Manual of Mental Disorders, DSM-IV-TR Version. These criteria use the self-reported experience of the patient and reported abnormalities in behavior and a comprehensive clinical assessment by a neuro-psychiatrist. After initial selection, to ensure the diagnostic reliability a systemic search into the case notes of the patients was made. Patients with questionable diagnosis, known organic disorder, or mental retardation were excluded. The remainder of the patients were interviewed by the psychiatrist to ascertain whether patients met DSM-1V-TR criteria for schizophrenia. After confirmation of schizophrenia diagnoses, patients were further assessed for positive and negative symptoms using the Positive and Negative Syndrome Scale (PANSS) involving further clinical interview, cognitive testing, motor assessment, and careful review of medical and historical records as described by Kay et al. [40]. This assessment procedure applied to the PANSS includes 30-item and 7-point rating instruments. Each item on the PANSS is accompanied by a complete definition as well as detailed anchoring criteria for all seven rating points, which represent increasing levels of psychopathology: 1 = absent, 2 = minimal, $3=$ mild, $4=$ moderate, $5=$ moderate-severe, $6=$ severe, and $7=$ extreme. Of the 30 psychiatric 
parameters assessed on the PANSS, 7 parameters (delusions, conceptual disorganization, hallucinatory behavior, excitement, grandiosity, suspiciousness, hostility) were chosen a priori to constitute a Positive Scale, seven others (blunted affect, emotional withdrawal, poor rapport, passive-apathetic social withdrawal, difficulty in abstract thinking, lack of spontaneity and flow of conversation, stereotyped thinking) a Negative Scale, and the remaining 16 a general psychopathology scale. The PANSS was scored by summation of ratings across items, such that the potential ranges were 7-49 for the Positive and Negative Scales. The assessment was conducted by two trained psychiatrists independently and almost the same rating was obtained for each patient by both the psychiatrists.

Based on the above criteria, only 180 patients scoring 7-49 either for positive or negative symptoms were included in this study. Among the confirmed 180 cases there were 52 females and 128 males with a mean age of $39 \pm 12.5$ years and mean disease duration of $9 \pm 4.5$ years. Age of onset of disease ranged from 19 to 64 years. The female to male ratio of schizophrenia patients in our study was $1: 2.5$.

The matched control group consisted of 200 healthy unrelated voluntary blood donors (aged 26-55 years) from the same Saudi population. Each control subject was interviewed and examined by a psychiatrist to rule out subjects with a family history of any psychiatric illness. A number of baseline parameters to rule out any psychotic illness were adopted as described by Johnstone et al. [41]. Controls subjects less than 26 years old and having first- or second-degree relatives with schizophrenia or any psychiatric disorder or with past or present involvement in substance abuse were excluded. The control group consisted of 50 females and 150 males with mean age of 36 \pm 10 years. This study was approved by the ethical committee of the hospital and informed consent was obtained from each subject.

\section{Genotyping}

Genomic DNA was extracted from the blood of schizophrenia patients and controls using the QIAamp DNA mini kit (Qiagen CA, USA). The genotypes of the APOE polymorphisms were determined using the ApoE StripAssay kit based on polymerase chain reaction (PCR) and reverse-hybridization technique (ViennaLab Labordiagnostika $\mathrm{GmbH}$, Vienna, Austria). The procedure included three steps: (1) DNA isolation, (2) PCR amplification using biotinylated primers, (3) hybridization of amplification product to a test strip containing allele-specific oligonucleotide probes immobilized as an array of parallel lines. Bound biotinylated sequences were detected using streptavidin-alkaline phosphatase and color substrates. To cross-check the results the genotypes of the APOE polymorphisms were also determined by $P C R$ and restriction fragment length polymorphism (RFLP) technique. Primers were designed on the basis of the sequence data for APOE available in GenBank to amplify the coding sequence of APOE. The PCR was performed using PuRe Taq Ready-To-Go PCR Beads (GE Healthcare, UK) with primers as described earlier [25].

200-300 ng of genomic DNA was used as a template in $25 \mu \mathrm{l}$ reaction volume. Genomic DNA was amplified for 40 cycles. Each cycle consisted of: $94^{\circ} \mathrm{C}$ for $30 \mathrm{~s}, 68^{\circ} \mathrm{C}$ for $10 \mathrm{~s}, 72^{\circ} \mathrm{C}$ for $1 \mathrm{~min}$; PCR products obtained were separated by electrophoresis on $1.5 \%$ agarose gel in TAE buffer, visualized by ethidium bromide fluorescence. Fragments with the expected size were cut from the gel, purified using the GFX PCR DNA Gel band purification kit (GE Healthcare, UK). Purified DNA was digested with Cfo I (Hha I) enzyme, separated by agarose gel electrophoresis to identify the genotype. On the basis of size and number of various fragments generated, APOE genotypes were determined as $\varepsilon 2 / \varepsilon 2$ with $144 \mathrm{bp}$ and $96 \mathrm{bp}$, $\varepsilon 3 / \varepsilon 3$ with $144 \mathrm{bp}$ and $48 \mathrm{bp}, \varepsilon 4 / \varepsilon 4$ with $72 \mathrm{bp}$ and $48 \mathrm{bp}, \varepsilon 2 / \varepsilon 3$ with $144 \mathrm{bp}, 96 \mathrm{bp}$ and $48 \mathrm{bp}$, $\varepsilon 3 / \varepsilon 4$ with $144 \mathrm{bp}, 72 \mathrm{bp}$ and $48 \mathrm{bp}$, and $\varepsilon 2 / \varepsilon 4$ with 144 bp, 96 bp, 72 bp and 48 bp fragments. The prevalence of various genotypes in patients and controls was determined. Complete matching of results was obtained following both of the above-mentioned procedures.

\section{Statistical analysis}

Frequencies of various alleles and genotypes for each polymorphism were compared between patients and controls and analyzed by Fisher's exact test, and $p$-values $<0.05$ were considered as significant. The strength of the association of disease with respect to a particular allele/genotype is expressed by the odd ratio interpreted as relative risk (RR) according to the method of Woolf as outlined by Schallreuter et al. [42]. The RR was calculated only for those alleles and genotype which were increased or decreased in schizophrenia patients as compared to normal Saudis.

Etiologic fraction (EF) indicates the hypothetical genetic component of the disease. Values $>0.0$ are of significance. It was calculated for a positive association $(R R>1)$ [43].

Preventive fraction (PF) indicates the hypothetical protective effect of one specific allele/ genotype for the disease. It was calculated for a negative association $(R R<1)$ [43]. Values $<1.0$ indicated the protective effect of the genotype/allele against manifestation of the disease. 


\section{Results}

The results of frequency of APOE alleles and genotypes in the schizophrenia patients and the control subjects are summarized in Tables I and II. In both schizophrenia patient and control groups the genotype distributions were in Hardy-Weinberg equilibrium. The $\varepsilon 2$ allele was present in $9.17 \%$ of schizophrenia patients and altogether absent in controls $(p=0.0001)$. The frequency of $\varepsilon 3$ alleles was significantly lower in schizophrenia patients $(83.33 \%)$ compared with that in controls (95.75\%, $p=0.0001, \mathrm{RR}=0.222, \mathrm{PF}=0.606)$. On the other hand, the frequency of allele $\varepsilon 4$ was higher in patients compared with that in controls $(p=$ $0.06, \mathrm{RR}=1.826, \mathrm{EF}=0.277$ ) (Table I). Our study on various genotypes of APOE also showed variations in patient and control groups. The prevalence of $\varepsilon 3 / \varepsilon 3, \varepsilon 3 / \varepsilon 4, \varepsilon 2 / \varepsilon 3$, and $\varepsilon 2 / \varepsilon 4$ was $70.0,11.67$, 15 , and $3.33 \%$ in patients and $91.5,8.5,0$ and $0 \%$ in the control group, respectively. Though the frequency of $\varepsilon 3 / \varepsilon 3$ genotype was higher in both the test and control Saudi population, the statistical analysis of data showed a significant difference in $\varepsilon 3 / \varepsilon 3$ genotype frequency between patients and controls, being higher in controls than in patients $(p=0.0001, \mathrm{RR}=0.217, \mathrm{PF}=0.598)$. The difference in the frequencies of the genotype $\varepsilon 3 / \varepsilon 4$ was not statistically significant between the two groups $(p=0.31, \mathrm{RR}=1.449, \mathrm{EF}=0.171)$. The genotypes $\varepsilon 2 /$ $\varepsilon 3$ and $\varepsilon 2 / \varepsilon 4$ were present in $15 \%$ and $3.33 \%$ of patients, respectively, but totally absent in the controls ( $p=0.0001, p=0.01$, respectively). The genotypes $\varepsilon 2 / \varepsilon 2$ and $\varepsilon 4 / \varepsilon 4$ were absent in both patient and control groups. These results indicated that allele $\varepsilon 2$ and genotypes $\varepsilon 2 / \varepsilon 3$ and $\varepsilon 2 / \varepsilon 4$ are associated with schizophrenia and may be a risk factor while allele $\varepsilon 3$ and genotype $\varepsilon 3 / \varepsilon 3$ may be protective for schizophrenia in Saudis. The frequency distribution of genotypes and alleles of APOE polymorphism were not significantly different in male and female patients, indicating that gender plays no role in genotype/allele distributions among Sau-

Table I. Apolipoprotein E genotype/allele frequencies in schizophrenia patients and matched controls

\begin{tabular}{|c|c|c|c|c|c|c|c|}
\hline \multirow{2}{*}{$\begin{array}{l}\text { Genotype/ } \\
\text { allele }\end{array}$} & \multicolumn{2}{|c|}{ Schizophrenia $(N=180)$} & \multicolumn{2}{|c|}{ Control $(N=200)$} & \multirow[t]{2}{*}{ Value of $p$} & \multirow[t]{2}{*}{$\mathrm{RR}$} & \multirow[t]{2}{*}{$\mathrm{EF}^{*} / \mathrm{PF}$} \\
\hline & $N$ & Frequency (\%) & $N$ & Frequency (\%) & & & \\
\hline$\varepsilon 3 / \varepsilon 3$ & 126 & 70.00 & 183 & 91.50 & $0.0001^{*}$ & 0.217 & 0.598 \\
\hline$\varepsilon 3 / \varepsilon 4$ & 21 & 11.67 & 17 & 8.50 & 0.3100 & 1.449 & $0.171^{*}$ \\
\hline$\varepsilon 2 / \varepsilon 3$ & 27 & 15.00 & 0 & 0 & $0.0001^{*}$ & - & - \\
\hline$\varepsilon 2 / \varepsilon 4$ & 6 & 3.33 & 0 & 0 & $0.0100^{*}$ & - & - \\
\hline$\varepsilon 2 / \varepsilon 2$ & 0 & 0 & 0 & 0 & - & - & - \\
\hline$\varepsilon 4 / \varepsilon 4$ & 0 & 0 & 0 & 0 & - & - & - \\
\hline$\varepsilon 3$ & 300 & 83.33 & 383 & 95.75 & $0.0001 *$ & 0.222 & 0.606 \\
\hline$\varepsilon 4$ & 27 & 7.50 & 17 & 4.25 & 0.0600 & 1.826 & $0.277^{\star}$ \\
\hline$\varepsilon 2$ & 33 & 9.17 & 0 & 0 & $0.0001 *$ & - & - \\
\hline
\end{tabular}

$N$ - Number of subjects, "statistically significant, EF- etiological fraction, PF - preventive fraction.

Table II. Comparison of apolipoprotein E genotypes and alleles with negative or positive symptoms in schizophrenia patients and controls

\begin{tabular}{|c|c|c|c|c|c|c|}
\hline \multirow{2}{*}{$\begin{array}{l}\text { Genotype/ } \\
\text { allele }\end{array}$} & \multicolumn{2}{|c|}{ With negative symptoms $(N=94)$} & \multicolumn{2}{|c|}{ With positive symptoms $(N=86)$} & \multicolumn{2}{|c|}{ Control $(N=200)$} \\
\hline & $N$ & Frequency (\%) & $N$ & Frequency (\%) & $N$ & Frequency (\%) \\
\hline$\varepsilon 3 / \varepsilon 3$ & 71 & $75.53 * *$ & 55 & $63.95^{*}$ & 183 & 91.50 \\
\hline$\varepsilon 3 / \varepsilon 4$ & 8 & 8.51 & 13 & 15.12 & 17 & 8.50 \\
\hline$\varepsilon 2 / \varepsilon 3$ & 11 & $11.70^{*}$ & 16 & $18.60^{*}$ & 0 & 0 \\
\hline$\varepsilon 2 / \varepsilon 4$ & 4 & $4.26^{*}$ & 2 & 2.33 & 0 & 0 \\
\hline$\varepsilon 3$ & 161 & $85.64^{*}$ & 139 & $80.81^{\star}$ & 383 & 95.75 \\
\hline$\varepsilon 4$ & 12 & 6.38 & 15 & $8.72^{*}$ & 17 & 4.25 \\
\hline$\varepsilon 2$ & 15 & $7.98^{*}$ & 18 & $10.47^{*}$ & 0 & 0 \\
\hline
\end{tabular}

-P-value $<0.05$ as compared to the frequency in patients with positive symptoms. ${ }^{*}$-value $<0.05$ as compared to the frequency in controls, $N$ - number of subjects. 
di patients with schizophrenia. The APOE $\varepsilon 2$ allele was associated with age of onset of schizophrenia $(p=0.001)$. The groups of patients with genotypes $\varepsilon 2 / \varepsilon 3$ and $\varepsilon 2 / \varepsilon 4$ had a lower age of onset $(21 \pm 4$ years) than the patients with genotypes $\varepsilon 3 / \varepsilon 3$ and $\varepsilon 3 / \varepsilon 4$ ( $31 \pm 10$ years).

The difference in the frequency distribution of APOE genotypes and alleles between the two types of schizophrenia was not significant except for the frequency of genotype $\varepsilon 3 / \varepsilon 3$, which was significantly higher in patients with negative symptoms compared with patients with positive symptoms (Table II). However, when compared with controls separately, a similar pattern was observed for both types of schizophrenia except that the frequency of allele $\varepsilon 4$ was significantly higher in patients with positive symptoms ( $p=0.045)$ but not in patients with negative symptoms.

\section{Discussion}

In this study we found that frequencies of various isoforms of APOE were significantly different between the Saudi schizophrenia patients and healthy controls (Table I). One interesting finding of this study is that significantly higher frequencies of allele $\varepsilon 2(p=0.0001)$ and heterozygous genotypes $\varepsilon 2 / \varepsilon 3(p=0.0001)$ and $\varepsilon 2 / \varepsilon 4$ $(p=0.010)$ were observed in Saudi schizophrenic patients, whereas allele $\varepsilon 2$ was completely absent in Saudi healthy controls. Moreover, patients with genotypes $\varepsilon 2 / \varepsilon 3$ and $\varepsilon 2 / \varepsilon 4$ had a lower age of onset than the patients with genotypes $\varepsilon 3 / \varepsilon 3$ and $\varepsilon 3 / \varepsilon 4$, indicating that the APOE $\varepsilon 2$ allele was associated with age of onset in schizophrenia $(p=0.001)$. Earlier studies reported low frequencies of allele $\varepsilon 2$ in control populations [44-51], while it was completely absent in healthy Saudis $[25,52]$ and South American Amerindians [53]. This study clearly suggests that carriers of APOE $\varepsilon 2 / \varepsilon 3$ and APOE $\varepsilon 2 / \varepsilon 4$ are at higher risk of developing schizophrenia. Our finding is in agreement with Schurhoff et al. [54], who reported that the APOE $\varepsilon 2 / \varepsilon 3$ genotype may confer higher susceptibility to schizophrenia in the French male population. Halford et al. [55] observed that American Caucasians with schizophrenia-associated tardive dyskinesia had significantly higher frequency of the APOE $\varepsilon 2$ allele. However, no such association was found in African-Americans, suggesting a definite role of race/ethnicity. Contrary to our findings, studies carried out on Korean [56] and Kuwaiti populations [37] showed a significant protective effect of APOE $\varepsilon 2$ against the development of schizophrenia. Kimura et al. [33] also observed a protective role of $\mathrm{APOE} \varepsilon 2$ against early onset schizophrenia in the Japanese population.

The mechanism by which APOE $\varepsilon 2$ affects susceptibility to schizophrenia is far from clear. Al- though schizophrenia is primarily considered to be a neurodevelopmental disease, there is a growing consensus that the disorder involves neurodegeneration [57]. The hypothesis of neurodegenerative change in schizophrenic patients has been supported by observation of increased vulnerability to apoptosis, increase in cell loss and reduced neuronal size as well as decreased expression of synaptic proteins in schizophrenia [58-60]. A meta-analysis of published work showed a clear association between APOE and neurodegenerative disorders [61]. Some studies reported higher frequency of APOE $\varepsilon 2$ in Parkinson's disease as compared to controls [62]. On the other hand, the possession of APOE $\varepsilon 2$ has been associated with late-onset Alzheimer's disease, longevity in Down's syndrome, protection against the development of dementia, and protection against early-onset schizophrenia $[33,37,56,63,64]$. The mechanism by which APOE participates in the different pathogenic processes remains to be elucidated. A definite role of APOE $\varepsilon 2$ in regulation of neuronal sprouting, regeneration and apoptosis has been demonstrated [64]. The APOE $\varepsilon 2$ isoform differs from the APOE $\varepsilon 3$ isoform by one amino acid, at position 158, with $\varepsilon 2$ containing cysteine and $\varepsilon 3$ containing arginine. This single amino acid difference results in markedly reduced/defective binding of APOE $\varepsilon 2$ to the low density lipoprotein family of receptors, which in turn results in profound metabolic consequences, particularly type III hyperlipidemia. Additionally, the two cysteines in APOE $\varepsilon 2$ (positions 112 and 158) permit APOE $\varepsilon 2$ to form disulfide-linked multimeric protein complexes. These unique properties of APOE $\varepsilon 2$ may contribute to its role in the etiology of neurological as well as coronary artery diseases.

The results of this study also showed significantly lower frequencies of allele $\varepsilon 3$ and genotype $\varepsilon 3 / \varepsilon 3$ among Saudi schizophrenic patients as compared to healthy controls (Table I), suggesting that the $\varepsilon 3$ allele confers protection against schizophrenia in the Saudi population. Our findings are in agreement with several published studies on other populations including Chinese [65], Finnish [66] and Serbian [38], in which decreased frequencies of genotype $\varepsilon 3 / \varepsilon 3$ and allele $\varepsilon 3$ were observed in schizophrenia patients compared to controls, and the effect was independent of sex and age of onset of illness. Kampman et al. [66] also suggested that the APOE $\varepsilon 3$ allele may function in a protective manner in later onset schizophrenia and its absence could be associated with higher risk for early-onset schizophrenia. The results of a recent study by Kecmanovič et al. [38] further strengthened the reports that the $\varepsilon 3$ allele could serve as a protective factor against symptoms more abundant in undifferentiated types of schizophrenia. In contradiction to these, some re- 
ports on schizophrenic patients from Taiwan [34], Korea [56] and Mexico [36] stated that the development of schizophrenia in these populations is associated with higher frequency of allele $\varepsilon 3$. Yet some other investigators found no association between the frequency of APOE $\varepsilon 3$ and schizophrenia [30-32, 67-70]. This inconsistency in published data may be attributed to small sample size, problems of sample stratification, mismatch between cases and controls, diagnostic criteria of the disease, clinical status of patients/severity of disease and method of detection of APOE (protein isoelectric focusing or PCR-based genotyping).

The frequency of the $\varepsilon 4$ allele was also higher in Saudi schizophrenia patients as compared to controls, a difference which was just short of significance $(p=0.06)$. However, upon stratification of patients with positive symptoms and with negative symptoms, the frequency of the $\varepsilon 4$ allele was significantly higher in schizophrenia patients with positive symptoms as compared with that in controls. These results point to a higher risk of the disease among APOE $\varepsilon 4$ carriers. A significant role of APOE $\varepsilon 4$ in the pathogenesis of schizophrenia was first reported by Harrington et al. [28]. However subsequent studies revealed conflicting results $[31,34,65,66,70-74]$. A recent meta-analysis of published data clearly showed that APOE $\varepsilon 4$ is significantly associated with schizophrenia [75]. Moreover, an association between early age of onset in schizophrenia and higher frequencies of the $\varepsilon 4$ allele has also been reported $[31,66]$.

On the other hand, population-based studies from other geographical locations/ethnic groups failed to find any significant association of APOE $\varepsilon 4$ and schizophrenia [29, 30, 32-36, 69, 73, 76, 77].

Overall, APOE $\varepsilon 4$ has been shown to be a major risk factor for a variety of neurodevelopmental and neurodegenerative disorders including schizophrenia and Alzheimer's disease (AD). The mechanism by which carrying the APOE $\varepsilon 4$ allele translates to neuropathology remains elusive. The APOE plays a critical role in redistributing lipids among CNS cells for normal lipid homeostasis, repairing injured neurons, maintaining synapto-dendritic connections, and scavenging toxins [19]. In multiple pathways affecting neuropathology of neuropsychological disorders, APOE may act by itself or in concert with age, oxidative stress, ischemia and inflammation to cause neurological disorders, accelerating progression, altering prognosis, or lowering age of onset. The role of APOE $\varepsilon 4$ in diabetic peripheral neuropathy has been suggested by some investigators though it is still debated and needs further studies [78]. It has also been suggested that unique structural features of APOE $\varepsilon 4$ are responsible for $\varepsilon 4$-associated neuropathology
[79]. Although the structures of $\operatorname{APOE} \varepsilon 2, \varepsilon 3$, and $\varepsilon 4$ are in dynamic equilibrium, $\mathrm{APOE} \varepsilon 4$, which is detrimental in a variety of neurological disorders, is more likely to assume a pathological conformation. Importantly, $\varepsilon 4$ displays domain interaction and molten globule formation (the formation of stable, reactive intermediates with potentially pathological activities). APOE $\varepsilon 4$ uniquely undergoes neuron-specific proteolysis, resulting in bioactive toxic fragments that enter the cytosol, alter the cytoskeleton, disrupt mitochondrial energy balance, and cause cell death [80]. In recent years potential therapeutic strategies, including the use of "structure correctors" to convert APOE $\varepsilon 4$ to an "APOE $\varepsilon 3$-like" molecule, protease inhibitors to prevent the generation of toxic APOE $\varepsilon 4$ fragments, and "mitochondrial protectors", have been attempted to prevent cellular energy disruption.

Overall, the results of this study clearly suggest that all three isoforms of APOE play a role in the pathogenesis of schizophrenia, but the way these isoforms modify the onset and course of the disease warrants further studies.

\section{Acknowledgments}

The authors would like to thank S. Sadaf Rizvi and Mohammad Al-Asmari for their help in laboratory work.

\section{Conflict of interest}

The authors declare no conflict of interest.

\section{References}

1. Saha S, Chant D, Welham J, McGrath J. A systematic review of the prevalence of schizophrenia. PLoS Med 2005; 2: e141.

2. McGrath J, Saha S, Chant D, Welham J. Schizophrenia: a concise overview of incidence, prevalence, and mortality. Epidemiol Rev 2008; 30: 67-76.

3. Paek MJ, Kang UG. How many genes are involved in schizophrenia? A simple simulation. Prog Neuropsychopharmacol Biol Psychiatry 2012; 38: 302-9.

4. Ayalew M, Le-Niculescu H, Levey DF, et al. Convergent functional genomics of schizophrenia: from comprehensive understanding to genetic risk prediction. Mol Psychiatry 2012; 17: 887-905.

5. van Os J, Kapur S. Schizophrenia. Lancet 2009; 374: 635-45.

6. Binder EB. The genetic basis of mood and anxiety disorders - changing paradigms. Biology of Mood and Anxiety Disorders 2012; 2: 17.

7. Palmer CGS, Hsieh H, Reed EF, et al. HLA-B maternal-fetal genotype matching increases risk of schizophrenia. Am J Hum Genet 2006; 79: 710-5.

8. Honer WG, Falkai P, Chen C, et al. Synaptic and plasticity-associated proteins in anterior frontal cortex in severe mental illness. Neuroscience 1999; 91: 1247-55.

9. Rosoklija G, Toomayan G, Ellis SP, et al. Structural abnormalities of subicular dendrites in subjects with schizophrenia and mood disorders: preliminary findings. Arch Gen Psychiatry 2000; 57: 349-56. 
10. Tkachev D, Mimmack ML, Ryan MM, et al. Oligodendrocyte dysfunction in schizophrenia and bipolar disorder. Lancet 2003; 362: 798-805.

11. Pfrieger FW. Outsourcing in the brain: do neurons depends on cholesterol delivery by astrocytes? Bioessays 2003; 25: 72-8.

12. Funfschilling U, Saher G, Xiao L, Mobius W, Nave K. Survival of adult neurons lacking cholesterol synthesis in vivo. BMC Neurosciences 2007; 8: 1.

13. Laws SM, Hone E, Gandy S, Martins RN. Expanding the association between the APOE gene and the risk of Alzheimer's disease: possible roles for APOE promoter polymorphisms and alterations in APOE transcription. J Neurochem 2003; 84: 1215-36.

14. Burchardt P, Zurawski J, Zuchoski B, et al. Low-density lipoprotein, its susceptibility to oxidation and the role of lipoprotein-b associated phospholipase A2 and carboxy ester lipases in atherosclerotic plaque formation. Arch Med Sci 2013; 9: 151-8.

15. Dietschy JM, Turley SD. Cholesterol metabolism in the brain. Curr Opin Lipidol 2001; 12: 105-12.

16. Hayashi H, Campenot RB, Vance DE, Vance JE. Glial lipoproteins stimulate axon growth of central nervous system neurons in compartmented cultures. J Biol Chem 2004; 279: 14009-15.

17. Dean B, Laws SM, Hone E, et al. Increased levels of apolipoprotein $\mathrm{E}$ in the frontal cortex of subjects with schizophrenia. Biol Psychiatry 2003; 54: 616-22.

18. Digney A, Keriakous D, Scarr E, Thomas E, Dean B. Differential changes in apolipoprotein $E$ in schizophrenia and bipolar I disorder. Biol Psychiatry 2005; 57: 711-5.

19. Vila-Rodriguez F, Honer WG, Innis SM, Wellington $C L$, Beasley CL. ApoE and cholesterol in schizophrenia and bipolar disorders: comparison of grey and white matter and relation with APOE genotype. J Psychiatry Neurosci 2011; 36: 47-55.

20. Artiga MJ, Bullido MJ, Sastre I, et al. Allelic polymorphisms in the transcriptional regulatory region of apolipoprotein E gene. FEBS Lett 1998; 421: 105-8.

21. Utermann G, Hees M, Steinmetz A. Polymorphism of apolipoprotein $\mathrm{E}$ and occurrence of dysbetalipoproteinaemia in man. Nature 1977; 269: 604-7.

22. Hatters DM, Peters-Libeu CA, Weisgraber KH. Apolipoprotein $\mathrm{E}$ structure: insights into function. Trends Biochem Sci 2006; 31: 445-54.

23. Yin R, Pan S, Wu J, Lin W, Yang D. Apolipoprotein E gene polymorphism and serum lipid levels in the Guangxi Hei Yi Zhuang and Han populations. Exp Biol Med (Maywood) 2008; 233: 409-18.

24. Raygani AV, Zahrai M, Raygani AV, et al. Association between apolipoprotein $\mathrm{E}$ polymorphism and Alzheimer disease in Tehran, Iran. Neurosci Lett 2005; 375: 1-6.

25. Al-Dabbagh NM, Al-Dohayan N, Arfin M, Tariq M. Apolipoprotein $\mathrm{E}$ polymorphisms and primary glaucoma in Saudis. Mol Vis 2009; 15: 912-9.

26. Korwek KM, Trotter JH, LaDu MJ, Sullivan PM, Weeber EJ. ApoE isoform-dependent changes in hippocampal synaptic function. Mol Degen 2009; 4: 21.

27. Risacher SL, Kim S, Shen L, et al. The role of apolipoprotein $\mathrm{E}$ (APOE) genotype in early mild cognitive impairment (E-MCI). Front Aging Neurosci 2013; 5: 11

28. Harrington $\mathrm{CR}$, Roth $\mathrm{M}$, Xuereb $\mathrm{JH}$, et al. Apolipoprotein E type epsilon 4 allele frequency is increased in patients with schizophrenia. Neurosci Lett 1995; 202: 101-4.

29. Jönsson E, Lannfelt L, Engvall B, Sedvall G. Lack of association between schizophrenia and the apolipoprotein $\mathrm{E}$ epsilon 4 allele. Eur Arch Psychiatry Clin Neurosci 1996; 246: $182-4$
30. Zhu S, Nöthen MM, Uhlhaas S, et al. Apolipoprotein E genotype distribution in schizophrenia. Psychiatr Genet 1996; 6: 75-9.

31. Arnold SE, Joo E, Martinoli MG, et al. Apolipoprotein E genotype in schizophrenia: frequency, age of onset, and neuropathologic features. Neuroreport 1997; 8: 1523-6.

32. Sorbi S, Nacmias B, Tedde A, et al. No implication of apolipoprotein $\mathrm{E}$ polymorphism in Italian schizophrenic patients. Neurosci Lett 1998; 244: 118-20.

33. Kimura T, Yokota S, Igata-Yi R, Shono M, Takamatsu J, Miyakawa T. Apolipoprotein E epsilon2 allele and early onset schizophrenia. Neurosci Lett 1997; 231: 53-5.

34. Chen JY, Hong CJ, Chiu HJ, et al. Apolipoprotein E genotype and schizophrenia. Neuropsychobiology 1999; 39: 141-3.

35. Xu MQ, St Clair D, He L. Meta-analysis of association between ApoE epsilon4 allele and schizophrenia. Schizophr Res 2006; 84: 228-35.

36. Tovilla-Zarate C, Medellin BC, Fresan A, et al. APOE-epsilon3 and APOE-219G haplotypes increase the risk for schizophrenia in sibling pairs. J Neuropsychiatry Clin Neurosci 2009; 21: 440-4.

37. Akanji AO, Ohaeri JU, Al-Shammri SN, Fatania HR. Apolipoprotein E polymorphism and clinical disease phenotypes in Arab patients with schizophrenia. Neuropsychobiology 2009; 60: 67-72.

38. Kecmanović M, Dobricić V, Dimitrijević R, et al. Schizophrenia and apolipoprotein $E$ gene polymorphism in Serbian population. Int J Neurosci 2010; 120: 502-6.

39. Al-Khathami AD, Ogbeide DO. Prevalence of mental illness among Saudi adult primary-care patients in central Saudi Arabia. Saudi Med J 2002; 23: 721-4.

40. Kay SR, Fiszbein A, Opler LA. The positive and negative syndrome scale (PANSS) for schizophrenia. Schizophr Bull 1987; 13: 261-76.

41. Johnstone EC, Ebmeier KP, Miller P, et al. Predicting schizophrenia: findings from the Edinburgh High-Risk Study. Br J Psychiatry 2005; 186: 18-25.

42. Schallreuter KU, Levenig C, Kuhnl P, et al. Histocompatability antigens in vitiligo: Hamburg study on 102 patients from Northern Germany. Dermatology 1993; 187: 186-92.

43. Savejgaard A, Platz P, Ryder LP. HLA and disease 1982. A survey. Immunol Rev 1983; 70: 193-218.

44. Senanarong V, Harnphadungkit K, Lertrit P, et al. Experience of ApoE study in Thai elderly. Med Assoc Thai 2001; 84: 182-7.

45. Tsunoda K, Harihara S, Dashnyam B, et al. Apolipoprotein $\mathrm{E}$ and $\mathrm{H}$ polymorphisms in Mongolian Buryat: allele frequencies and relationship with plasma lipid levels. Hum Biol 2002; 74: 659-71.

46. Tan CE, Tai ES, Tan CS, et al. APOE polymorphism and lipid profile in three ethnic groups in the Singapore population. Atherosclerosis 2003; 170: 253-60.

47. Errera FI, Silva ME, Yeh E, et al. Effect of polymorphisms of the MTHFR and APOE genes on susceptibility to diabetes and severity of diabetic retinopathy in Brazilian patients. Braz J Med Biol Res 2006; 39: 883-8.

48. Singh PP, Singh M, Mastana SS. APOE distribution in world populations with new data from India and the UK. Ann Hum Biol 2006; 33: 279-308.

49. Mahfouz RA, Sabbagh AS, Zahed LF, et al. Apolipoprotein E gene polymorphism and allele frequencies in the Lebanese population. Mol Biol Rep 2006; 33: 145-9.

50. Svobodova H, Kucerai F, Štulci T, et al. Apolipoprotein E gene polymorphism in the Mongolian population. Folia Biol (Praha) 2007; 53: 138-42. 
51. Abu Marrzoq AF, Sharif FA, Abed AA. Relationship between ApoE gene polymorphism and coronary heart disease in Gaza Strip. J Cardiovasc Dis Res 2011; 2: 29-35.

52. Al-Khedhairy AA. Apolipoprotein E polymorphism in Saudis. Mol Biol Rep 2004; 31: 257-60.

53. Marin GB, Tavella MH, Guerreiro JF, Santos SEB, Zago MA. Absence of the E2 allele of apolipoprotein in Amerindians. Braz J Genet 1997; $20: 4$.

54. Schurhoff F, Krebs MO, Szoke A. Apolipoprotein E in schizophrenia: a French association study and metaanalysis. Am J Med Genet Part B Neuropsychiatric Genet 2003; 119B: 18-23.

55. Halford J, Mazeika G, Slifer S, et al. APOE2 allele increased in tardive dyskinesia. Mov Disord 2006; 21: 540-2.

56. Lee MK, Park AJ, Nam BY, Min KJ, Kee BS, Park DB. Apolipoprotein $\mathrm{E}$ genotype in Korean schizophrenic patients. Jorean Med Sci 2001; 16: 781-3.

57. Csernansky JG. Neurodegeneration in schizophrenia: evidence from in vivo neuroimaging studies. Sci World J 2007; 7: 135-43.

58. Akbarian S, Kim JJ, Pothin SG, Hetrick WP, Bunney WE, Jones EG. Maldistribution of interstitial neurons in prefrontal white matter of the brains of schizophrenic patients. Arch Gen Psychiatry 1996; 53: 425-36.

59. Eastwood SL, Cotter D, Harrison PJ. Cerebellar synaptic protein expression in schizophrenia. Neuroscience 2001; 105: 219-29.

60. Jarskog LF, Glantz LA, Gilmore JH, Lieberman JA. Apoptotic mechanisms in the pathophysiology of schizophrenia. Prog Neuropsychopharmacol Biol Psychiatry 2005; 29: 846-58.

61. Huang Y, Weisgraber KH, Mucke L, Mahley RW. Apolipoprotein E: diversity of cellular origins, structural and biophysical properties, and effects in Alzheimer's disease. Jol Neurosci 2004; 23: 189-204.

62. Pulkes T, Papsing C, Mahasirimongkol S, Busabaratana M, Kulkantrakorn K, Tiamkao S. Association between apolipoprotein E genotypes and Parkinson's disease. J Clin Neurosci 2011; 18: 1333-5.

63. Royston MC, Mann D, Pickering-Brown S, et al. ApoE2 allele, Down's syndrome, and dementia. Ann N Y Acad Sci 1996; 777: 255-9.

64. Rebeck GW, Kindy M, LaDu MJ. Apolipoprotein and Alzheimer's disease: the protective effect of ApoE2 and E3. J Alzheimers Dis 2002; 4: 145-54.

65. Liu W, Breen G, Zhang J, et al. Association of APOE gene with schizophrenia in Chinese: a possible risk factor in times of malnutrition. Schizophr Res 2003; 62: 225-30.

66. Kampman O, Anttila S, Illi A, et al. Apolipoprotein E polymorphism is associated with age of onset in schizophrenia. J Hum Genet 2004; 49: 355-9.

67. Joober R, Rouleau R, Fon E, et al. Apolipoprotein E genotype in schizophrenia. Am J Med Genet 1996; 67: 235.

68. Town T, Fallin D, Crawford F, Walsh S, Solomon S, MulIan M. Lack of association between the apolipoprotein $\mathrm{E}$ epsilon4 allele (APOE epsilon4) and chronic schizophrenia. Am J Med Genet 1997; 74: 451-52.

69. Powchik P, Friedman J, Haroutunian V, et al. Apolipoprotein E4 in schizophrenia: a study of one hundred sixteen cases with neuropathological examination. Biol Psychiatry 1997; 42: 296-8.

70. Kimura T, Shono M, Yokota S, et al. Apolipoprotein E epsilon4 and tardive dyskinesia in a Japanese population. J Psychiatr Res 2000; 34: 329-32.

71. Pickar D, Malhotra AK, Rooney W, Breier A, Goldman D. Apolipoprotein E epsilon 4 and clinical phenotype in schizophrenia. Lancet 1997; 350: 930-1.
72. Durany N, Riederer P, Cruz-Sánchez FF. Apolipoprotein E genotype in Spanish schizophrenic patients. Psychiatr Genet 2000; 10: 73-7.

73. Hong CJ, Yu YW, Lin CH, et al. Association study of apolipoprotein E epsilon4 with clinical phenotype and clozapine response in schizophrenia. Neuropsychobiology 2000; 42: 172-4.

74. Sáiz PA, Morales B, G-Portilla MP, et al. Apolipoprotein E genotype and schizophrenia: further negative evidence. Acta Psychiatr Scand 2002; 105: 71-5.

75. Allen NC, Bagade S, McQueen MB, et al. Systematic meta-analyses and field synopsis of genetic association studies in schizophrenia: the SzGene database. Nat Genet 2008; 40: 827-34.

76. Thibaut F, Coron B, Hannequin D, et al. No association of apolipoprotein epsilon 4 allele with schizophrenia even in cognitively impaired patients. Schizophr Res 1998; 30: 149-53.

77. Thibaut F, Van Der Elst A, Campion D, et al. Apolipoprotein E-varepsilon4 frequency in deficit schizophrenia. Eur Psychiatry 1999; 14: 148-51.

78. Monastiriotis C, Papanas N, Veletza S, Maltezos E. APOE gene polymorphisms and diabetic peripheral neuropathy. Arch Med Sci 2012; 8: 583-8.

79. Mahley RW, Weisgraber KH, Huang Y. Apolipoprotein E4 a causative factor and therapeutic target in neuropathology, including Alzheimer's disease. Proc Natl Acad Sci USA 2006;103: 5644-51.

80. Brecht WJ, Harris FM, Chang S, et al. Neuron-specific apolipoprotein E4 proteolysis is associated with increased Tau phosphorylation in brains of transgenic mice. J Neurosci 2004; 24: 2527-34 